\title{
Genetic characterization of Mytilus coruscus and $M$. galloprovincialis using microsatellite markers
}

\author{
J.H. Kang ${ }^{1}$, J.M. Lee ${ }^{2}$, E.S. Noh ${ }^{1}$, J.Y. Park ${ }^{1}$ and C.M. An ${ }^{1}$ \\ ${ }^{1}$ Biotechnology Research Division, NFRDI, Busan, Republic of Korea \\ ${ }^{2}$ Gyeongsangnam-do Fisheries Resources Research Institute, Tongyoung, Korea \\ Corresponding author: J.H. Kang \\ E-mail: genetics@korea.kr
}

Genet. Mol. Res. 12 (4): 5494-5505 (2013)

Received April 29, 2013

Accepted October 22, 2013

Published November 13, 2013

DOI http://dx.doi.org/10.4238/2013.November.13.2

\begin{abstract}
Korean (hard-shelled) mussels (Mytilus coruscus) are an economically important endemic marine bivalve mollusk of Korea; yet, the population has rapidly declined because of overharvesting and habitat competition from the invasive Mytilus galloprovincialis species. The population structures of $M$. coruscus and $M$. galloprovincialis were analyzed by next-generation sequencing using 5 microsatellite markers specifically developed for M. coruscus. M. galloprovincialis had an average of 5.4 alleles per locus (range $=2-10$ ), with an average allelic richness of 4.9 per locus (range $=2.0-9.3$ ). M. coruscus had an average of 5.7 alleles per locus (range $=2-13$ ), with an average allelic richness of 5.2 per locus (range $=2.0-11.9$ ). Excessive homozygosity was observed at 3 loci, which was assumed to be due to the presence of null alleles at these loci. Pairwise multilocus $F_{\mathrm{ST}}$ estimates showed that the $M$. coruscus and $M$. galloprovincialis populations were clearly separated. Six populations of $M$. galloprovincialis from the western, eastern, and southern coast of Korea formed 2 separate clusters, indicating that more than 2 populations of $M$. galloprovincialis have been introduced to the Korean Peninsula. Hybrids between $M$. coruscus
\end{abstract}


and M. galloprovincialis were not identified, probably because of genetic differences or different habitat preferences. Further genetic information is required to perform selective breeding, population management, and restoration of $M$. coruscus.

Key words: Mytilus coruscus; Mytilus galloprovincialis; Microsatellite; Populations

\section{INTRODUCTION}

The Korean mussel, Mytilus coruscus (also termed "hard-shelled mussel), is an economically important marine bivalve mollusk in Korea; however, the population of this species is in rapid decline because of overharvesting and habitat competition from the invasive species Mytilus galloprovincialis (MIFAFF, 2003). M. galloprovincialis originates from the Mediterranean, but has invaded a broad geographic area, including the European shores, the Pacific coasts of Asia and North America, and the coasts of South Africa and Australia (Sanjuan et al., 1997), along with many other parts of the world (Hilbish et al., 2000; Wonham, 2004; Lockwood and Somero, 2011). In general, this mussel has an antitropical distribution, primarily inhabiting the temperate zones of the northern and southern hemispheres (Hilbish et al., 2000).

The distribution of Mytilus species across the globe is facilitated by certain advantageous life-history characteristics. For instance, their planktonic larval stage enables them to be passively transported in the ballast water of commercial ships. The byssal threads produced by juveniles and adults allow transport on hard substrates. In addition, they are highly palatable and are relatively easy to culture (Wonham, 2004). M. galloprovincialis is very competitive, and has become the dominant species in many areas. This species has even replaced native species, such as the limpet (Scutellastra granularis) from primary rocky habitat along the coast of South African (Griffiths et al., 1992; Hockey and Van Erkom Schurink, 1992; Steffani et al., 2005). In addition, hybrids have been detected between M. galloprovincialis and $M$. trossulus, as well as M. edulus (Suchanek et al., 1997; Inoue et al., 1997; Rawson et al., 1999).

It is believed that M. galloprovincialis was introduced to the Korean Peninsula via the ballast water of ships from Western Europe at least 50 years ago. Although M. galloprovincialis is currently a dominant mussel species in the natural environment and aquaculture of Korea, restoration and population recovery of the endemic $M$. coruscus species is being petitioned, partly because of its economically advantageous traits, such as its large size and high-quality meat. However, genetic information about the population dynamics and molecular phylogeny of M. coruscus and M. galloprovincialis around the Korean Peninsula is not available.

Microsatellites (MSs), also known as simple sequence repeats, are versatile molecular tools used to determine the parentage, genetic structure, and gene flow patterning of species, and may be used to determine the origins of introduced populations (Jarne and Lagoda, 1996; Zane et al., 2002). The development of MS markers is a lengthy, labor-intensive, and expensive procedure, requiring the screening of genomic libraries and using repetitive probes followed by the sequencing of positive clones to develop locus-specific primers (Hamilton et al., 1999).

Next-generation sequencing (NGS) is a relatively new technique that is used to generate gigabases of sequence data in a single run. This technique is able to capture individual MSs and identify flanking sequences that may be used for polymerase chain reaction (PCR) primer 
design, facilitating the rapid and cost-efficient parallel processing of millions of templates (Abdelkrim et al., 2009; Santana et al., 2009; Zalapa et al., 2012). Recently, NGS has been effectively used to define the MS markers of marine organisms (Saarinen and Austin, 2010; Greenley et al., 2012; Kang et al., 2012; Wang et al., 2012). Another advantage of using NGS for MS markers is that a large number of candidate markers may be identified by pyrosequencing; thus, facilitating the use of identified MS markers in higher cross-species transfer analyses of closely related species (Guichoux et al., 2011; Wang et al., 2012).

We recently used the NGS technique to developed 20 MS markers for M. coruscus. Among these MS markers, 5 polymorphic loci were amplified in M. galloprovincialis. In the present study, we analyzed 2 wild populations of $M$. coruscus and 6 wild populations of $M$. galloprovincialis collected along the entire Korean Peninsula. The 5 MS markers were used to investigate the population structure of the 2 species; specifically we assessed the genetic relationships within and across populations and examined the possibility of hybrids between these 2 species.

\section{MATERIAL AND METHODS}

\section{Samples and DNA preparation}

A total of 106 wild M. coruscus and 261 wild M. galloprovincialis specimens were collected from 2 and 6 areas, respectively, around the Korean Peninsula. The sampling locations are shown in Figure 1. The specimens were transported alive to the laboratory for DNA extraction. Total DNA was isolated from each sample using a MagExtractor MFX-6100 automated DNA extraction system (Toyobo, Osaka, Japan). The extracted genomic DNA was quantified using a Nanodrop ND-1000 spectrophotometer (Thermo Fisher Scientific, Barrington, IL, USA) and stored at $-20^{\circ} \mathrm{C}$ until use.

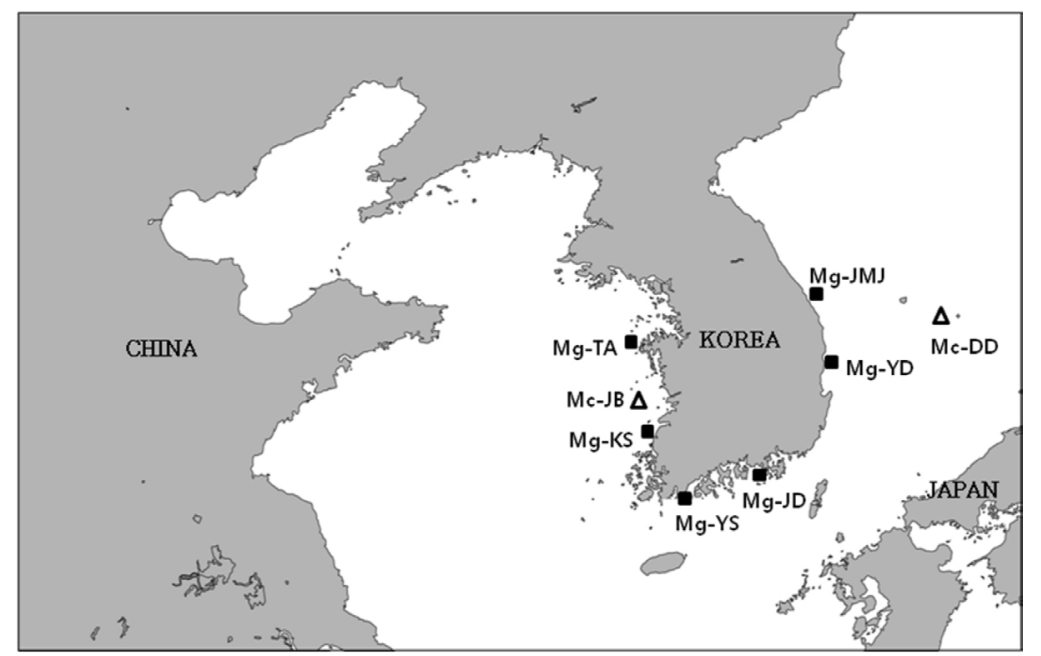

Figure 1. Geographical map showing locations and abbreviated names of Mytilus spp populations from Korea. The prefixes $\mathrm{Mg}$ and $\mathrm{Mc}$ represent M. galloprovincialis and M. coruscus, respectively. The abbreviations are as follows: Mg-TA (Taean), Mc-JB (Jeonbuk), Mg-KS (Kunsan), Mg-YS (Yeosu), Mg-JD (Jindong), Mg-YD (Youngdeuk), Mg-JMJ (Jumunjin), and Mc-DD (Dokdo). 


\section{Species identification}

To confirm species identity, 32 individuals from each sampling area were tested. The partial sequence of cytochrome oxidase subunit I (COI) gene was amplified by using the HCO2198 primer (5'-TAAACTTCAGGGTGACCAAAAAATCA-3') and the LCO1490 primer (5'-GGTCAACAAATCATAAAGATATTGG-3') set (Folmer et al., 1994). PCR was performed using a thermocycler (PTC-220, Bio-Rad, USA) in $25-\mu \mathrm{L}$ volumes, with 25 ng DNA, $0.2 \mathrm{U}$ of DNA polymerase (Ampli-Taq Gold; Applied Biosystems, Foster City, CA, USA), $250 \mu \mathrm{M}$ of each dNTP and 1X PCR buffer containing $1.5 \mathrm{mM} \mathrm{MgCl}_{2}$ and $10 \mathrm{pM}$ of each primer. PCR amplification consisted of initial denaturation at $93^{\circ} \mathrm{C}$ for $10 \mathrm{~min}$, followed by 35 cycles of denaturation at $93^{\circ} \mathrm{C}$ for $1 \mathrm{~min}$, annealing at $55^{\circ} \mathrm{C}$ for $1.5 \mathrm{~min}$, extension at $72^{\circ} \mathrm{C}$ for $1 \mathrm{~min}$, and a final extension at $72^{\circ} \mathrm{C}$ for $10 \mathrm{~min}$. The PCR fragments were purified using AMPure ${ }^{\mathrm{TM}}$ magnetic beads (Agencourt Bioscience, Beverly, MA, USA) following manufacturer protocols. Approximately 8-20 ng purified product was used as a template for sequencing using the ABI Big Dye $^{\circledR}$ Terminator v. 3.1, Cycle Sequencing Kit (Applied Biosystems).

\section{PCR and genotyping}

Five loci that were also amplified in M. galloprovincialis were used in this study. Detailed information about these primers is presented in Table 1. Each PCR contained 3 primer sets that were differentially labeled at the $5^{\prime}$ of the forward primer with either 6-FAM, NED, or HEX dyes (PE Applied Biosystems). PCR amplification was carried out in a $10-\mu \mathrm{L}$ reaction mixture containing 0.25 U Ex Taq DNA polymerase (TaKaRa Biomedical Inc., Shiga, Japan), 1X PCR buffer, $0.2 \mathrm{mM}$ dNTP mix, $10 \mathrm{pM}$ each, and 100 ng template DNA, using a PTC 200 DNA Engine (MJ Research, Waltham, MA, USA). PCR conditions were as follows: $11 \mathrm{~min}$ at $95^{\circ} \mathrm{C}$, followed by 35 cycles of $1 \mathrm{~min}$ at $94^{\circ} \mathrm{C}, 1 \mathrm{~min}$ at $54^{\circ} \mathrm{C}$ or $58^{\circ} \mathrm{C}$, and $1 \mathrm{~min}$ at $72^{\circ} \mathrm{C}$, with a final extension of $5 \mathrm{~min}$ at $72^{\circ} \mathrm{C}$. Microsatellite polymorphisms were screened using an ABI PRISM $3130 \mathrm{XL}$ automated DNA sequencer (Applied Biosystems), and alleles were designated according to PCR product size relative to a molecular size marker (GENESCAN 400 HD [ROX]; PE Applied Biosystems).

\begin{tabular}{|c|c|c|c|}
\hline Locus & Primer sequence $\left(5^{\prime} \rightarrow 3^{\prime}\right)$ & AT $\left({ }^{\circ} \mathrm{C}\right)$ & Motif \\
\hline Mc65-nfrdi & $\begin{array}{l}\text { HEX TTGTTGACATCGTTGTTGTTCT } \\
\text { TGAAACATCAATTACAAGTGCC }\end{array}$ & 54 & $(\mathrm{AG})_{14}$ \\
\hline Mc84-nfrdi & $\begin{array}{l}\text { NED TAAAATCAATAAATGTCCCGCT } \\
\text { ACAACAGTTCAAATGTCATTGC }\end{array}$ & 54 & $(\mathrm{AT})_{8}$ \\
\hline Mc137-nfrdi & $\begin{array}{l}\text { 6-FAM AATGTTCCATGCTAGTGTTCAA } \\
\text { CTTATCACAACACAGGTAGGCA }\end{array}$ & 58 & $(\mathrm{AT})_{9}$ \\
\hline Mc169-nfrdi & $\begin{array}{l}\text { NED TATTGAGTGTTTTTGAGAGGGG } \\
\text { TACTGCATGATTTTTGCTCATC }\end{array}$ & 54 & $(\mathrm{AT})_{9}$ \\
\hline Mc172-nfrdi & $\begin{array}{l}\text { HEX TTAGCAAATACCCTTAGGTGA } \\
\text { CTTTTGAAAATTCTGGATCTGC }\end{array}$ & 58 & $(\mathrm{AT})_{11}$ \\
\hline
\end{tabular}

\section{Statistical analysis}

The number of alleles per locus, allele frequency, and heterozygosity were calculated using Arlequin 3.0. Tests for population-wide linkage disequilibrium between pairs of loci and 
deviations from HWE were estimated using GENEPOP (ver.4.0; http://kimura.univ-montp2. $\mathrm{fr} /$ rousset/Genepop.htm), and the adjusted $\mathrm{P}$ values for both analyses were obtained using a sequential Bonferroni test for multiple comparisons. MICRO-CHECKER 2.2.3 was used to test the presence of null alleles. Allelic richness as a standardized measure of the number of alleles per locus, independent of the sample size, was calculated using FSTAT version 2.9.3. Possible geographical patterns in the distribution of genetic variability were analyzed using $F_{\mathrm{ST}}$ estimates and genetic distances between each pair of populations. The spatial variables were analyzed by using the principal coordinates of the neighbor matrices method (Legendre et al. 2009).

\section{RESULTS}

\section{Species identification and COI gene haplotypes}

Using a PCR primer set specific to the COI gene, amplified products of the expected size (606 bp) were obtained from both M. coruscus and M. galloprovincialis. Each of the sequenced PCR products from M. coruscus and M. galloprovincialis had $99 \%$ sequence identity with the reported COI gene sequence of the corresponding species (GenBank accession Nos.

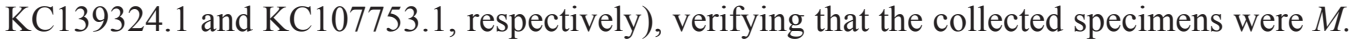
coruscus and M. galloprovincialis. A sequence comparison between the amplified COI gene fragments of the 2 species showed that they had $81 \%$ sequence identity. Sequence analysis of the COI gene from $M$. galloprovincialis revealed the presence of 26 variable sites and 8 haplotypes. In addition, 22 haplotypes were identified from the 2 populations of $M$. coruscus (data not shown).

\section{Genetic diversity of $M$. coruscus and M. galloprovincialis populations}

The genetic characterization indices estimated for the 2 populations of M. coruscus and 6 populations of M. galloprovincialis are summarized in Table 2. All loci were highly polymorphic; however, the degree of variability differed at each locus and for each species. For M. galloprovincialis, the number of alleles per locus ranged from 2 to 10 , with an average of 5.4, and the allelic richness per locus ranged from 2.0 to 9.3, with an average of 4.9. For $M$. coruscus, the number of alleles per locus ranged from 2 to 13, with an average of 5.7, and the allelic richness per locus ranged from 2.0 to 11.9, with an average of 5.2. Linkage disequilibrium was not observed between any pairs of loci $(\mathrm{P}>0.05)$, indicating that the markers were independent. The Hardy-Weinberg equilibrium (HWE) test, which shows deviation from expected heterozygosity $\left(H_{\mathrm{E}}\right)$, revealed significant deviation in the Mc65-nfrdi, Mc84-nfrdi, and Mc172-nfrdi loci after sequential Bonferroni's correction. The $H_{\mathrm{E}}$ was greater than the observed heterozygosity $\left(H_{\mathrm{O}}\right)$ at 3 loci, indicating excessive homozygosity at these loci. It was assumed that the excessive homozygosity at the 3 loci (Mc65-nfrdi, Mc84-nfrdi, and Mc169nfrdi) was the result of null alleles at these loci. The Mc137-nfrdi locus also showed greater $H_{\mathrm{E}}$ compared to $H_{\mathrm{O}}$; however, the deviation was only significant for the Mg-YS population. In contrast, the Mc172-nfrdi locus, which had no null alleles, showed greater $H_{\mathrm{O}}$ than $H_{\mathrm{E}}$ in 5 of the 8 populations, with significant deviation in both of the M. coruscus populations. Analysis of all 8 populations failed to identify alleles that would indicate the presence of hybrids between the 2 species. 
Table 2. Variability of alleles at five microsatellite loci.

\begin{tabular}{|c|c|c|c|c|c|c|c|}
\hline \multirow[t]{2}{*}{ Species } & \multirow[t]{2}{*}{ Populations } & \multicolumn{5}{|c|}{ Locus } & \multirow{2}{*}{$\begin{array}{c}\text { Mean of } \\
\text { all loci }\end{array}$} \\
\hline & & Mc65-nfrdi & Mc84-nfrdi & Mc137-nfrdi & Mc169-nfrdi & Mc172-nfrdi & \\
\hline \multirow[t]{56}{*}{ Mytilus galloprovincialis } & \multicolumn{7}{|l|}{$\mathrm{Mg}-\mathrm{KS}(\mathrm{N}=50)$} \\
\hline & $N_{\mathrm{A}}$ & 6 & 3 & 9 & 5 & 6 & 5.8 \\
\hline & $A_{\mathrm{R}}$ & 5.3 & 2.8 & 8.7 & 4.3 & 4.8 & 5.2 \\
\hline & $\mathrm{R}^{\mathrm{R}}$ & $160-174$ & $145-149$ & $130-148$ & $229-239$ & $160-182$ & \\
\hline & $H_{\mathrm{O}}$ & 0.184 & 0.045 & 0.792 & 0.120 & 0.388 & 0.306 \\
\hline & $H_{\mathrm{E}}$ & 0.330 & 0.528 & 0.831 & 0.349 & 0.466 & 0.501 \\
\hline & $F_{\text {IS }}$ & 0.443 & 0.914 & 0.047 & 0.656 & 0.169 & 0.446 \\
\hline & HWE & $0 * *$ & $0 * *$ & 0.082 & $0 * *$ & 0.017 & 0.020 \\
\hline & \multicolumn{7}{|l|}{ Mg-JD $(\mathrm{N}=50)$} \\
\hline & $N_{\mathrm{A}}$ & 5 & 3 & 8 & 6 & 5 & 5.4 \\
\hline & $A_{\mathrm{R}}^{\mathrm{A}}$ & 4.4 & 3.0 & 7.7 & 5.2 & 4.3 & 4.9 \\
\hline & $\mathrm{R}^{\mathrm{K}}$ & $160-174$ & $145-149$ & $130-146$ & $221-239$ & $160-182$ & \\
\hline & $H_{\mathrm{O}}$ & 0.277 & 0.100 & 0.750 & 0.204 & 0.300 & 0.326 \\
\hline & $H_{\mathrm{E}}$ & 0.604 & 0.474 & 0.824 & 0.404 & 0.362 & 0.534 \\
\hline & $F_{\text {IS }}$ & 0.542 & 0.789 & 0.090 & 0.495 & 0.171 & 0.417 \\
\hline & HWE & $0 * *$ & $0 * *$ & 0.413 & $0 * *$ & 0.170 & 0.117 \\
\hline & \multicolumn{7}{|l|}{ Mg-JMJ $(\mathrm{N}=33)$} \\
\hline & $N_{\mathrm{A}}$ & 4 & 2 & 9 & 5 & 5 & 5 \\
\hline & $A_{\mathrm{R}}^{\mathrm{A}}$ & 4.0 & 2.0 & 8.5 & 4.3 & 4.1 & 4.6 \\
\hline & $\mathrm{R}^{\mathrm{K}}$ & $160-174$ & $145-147$ & $130-148$ & $229-239$ & $160-182$ & \\
\hline & $H_{\mathrm{O}}$ & 0.182 & 0.100 & 0.667 & 0.125 & 0.438 & 0.302 \\
\hline & $H_{\mathrm{E}}$ & 0.643 & 0.463 & 0.808 & 0.328 & 0.419 & 0.532 \\
\hline & $F_{\text {IS }}^{\mathrm{E}}$ & 0.717 & 0.784 & 0.175 & 0.619 & -0.045 & 0.450 \\
\hline & HWE & $0 * *$ & $0 * *$ & 0.634 & $0 * *$ & 0.646 & 0.256 \\
\hline & \multicolumn{7}{|l|}{$\operatorname{Mg}-\mathrm{TA}(\mathrm{N}=34)$} \\
\hline & $N_{\mathrm{A}}$ & 5 & 3 & 8 & 6 & 3 & 5 \\
\hline & $A_{\mathrm{R}}^{\mathrm{A}}$ & 4.6 & 2.9 & 7.9 & 4.9 & 2.9 & 4.7 \\
\hline & $\mathrm{R}^{\mathrm{k}}$ & $160-172$ & $145-149$ & $130-148$ & $231-243$ & $176-180$ & \\
\hline & $H_{\mathrm{O}}$ & 0.118 & 0.065 & 0.818 & 0.156 & 0.125 & 0.256 \\
\hline & $H_{\mathrm{E}}$ & 0.644 & 0.539 & 0.821 & 0.207 & 0.177 & 0.478 \\
\hline & $F_{\text {IS }}$ & 0.817 & 0.880 & 0.003 & 0.246 & 0.294 & 0.448 \\
\hline & HWE & $0 * *$ & $0 * *$ & 0.836 & 0.094 & 0.098 & 0.206 \\
\hline & \multicolumn{7}{|l|}{$\operatorname{Mg}-\mathrm{YD}(\mathrm{N}=48)$} \\
\hline & $N_{\mathrm{A}}$ & 5 & 3 & 10 & 5 & 4 & 5.4 \\
\hline & $A_{\mathrm{R}}^{\mathrm{A}}$ & 4.8 & 3.0 & 9.3 & 4.6 & 3.4 & 5.0 \\
\hline & $\mathrm{R}$ & $160-172$ & $143-147$ & $130-148$ & $221-237$ & $176-182$ & \\
\hline & $H_{\mathrm{O}}$ & 0.146 & 0.179 & 0.783 & 0.152 & 0.188 & 0.290 \\
\hline & $H_{\mathrm{E}}$ & 0.438 & 0.548 & 0.875 & 0.329 & 0.177 & 0.473 \\
\hline & $F_{\text {IS }}$ & 0.667 & 0.673 & 0.105 & 0.538 & -0.060 & 0.385 \\
\hline & HWE & $0 * *$ & $0 * *$ & 0.099 & $0^{* *}$ & 1.000 & 0.220 \\
\hline & \multicolumn{7}{|l|}{$\operatorname{Mg}-Y S(N=48)$} \\
\hline & $N_{\mathrm{A}}$ & 6 & 4 & 8 & 5 & 5 & 5.6 \\
\hline & $A_{\mathrm{R}}$ & 4.7 & 4.0 & 7.8 & 4.6 & 3.9 & 5.0 \\
\hline & $\mathrm{R}^{\mathrm{k}}$ & $160-174$ & $143-149$ & $130-148$ & $221-237$ & $160-182$ & \\
\hline & $H_{\mathrm{O}}$ & 0.227 & 0.079 & 0.646 & 0.191 & 0.532 & 0.335 \\
\hline & $H_{\mathrm{E}}$ & 0.400 & 0.684 & 0.815 & 0.478 & 0.441 & 0.564 \\
\hline & $F_{\text {IS }}$ & 0.432 & 0.885 & 0.208 & 0.599 & -0.207 & 0.383 \\
\hline & HWE & $0.001 * *$ & $0 * *$ & $0.002 *$ & $0 * *$ & 0.637 & 0.128 \\
\hline & \multicolumn{7}{|l|}{ Mean of all populations } \\
\hline & $N_{\mathrm{A}}$ & 5.2 & 3.0 & 8.7 & 5.3 & 4.7 & 5.4 \\
\hline & $A_{\mathrm{R}}$ & 4.6 & 2.9 & 8.3 & 4.6 & 3.9 & 4.9 \\
\hline & $\mathrm{R}^{\mathrm{R}}$ & $160-174$ & $143-149$ & $130-148$ & $221-243$ & $160-182$ & \\
\hline & $H_{\mathrm{O}}$ & 0.189 & 0.095 & 0.743 & 0.158 & 0.329 & 0.303 \\
\hline & $H_{\mathrm{E}}$ & 0.510 & 0.539 & 0.829 & 0.349 & 0.340 & 0.514 \\
\hline & $F_{\text {IS }}$ & 0.603 & 0.821 & 0.105 & 0.526 & 0.054 & 0.422 \\
\hline & HWE & 0 & 0 & 0.344 & 0.016 & 0.428 & 0.158 \\
\hline
\end{tabular}




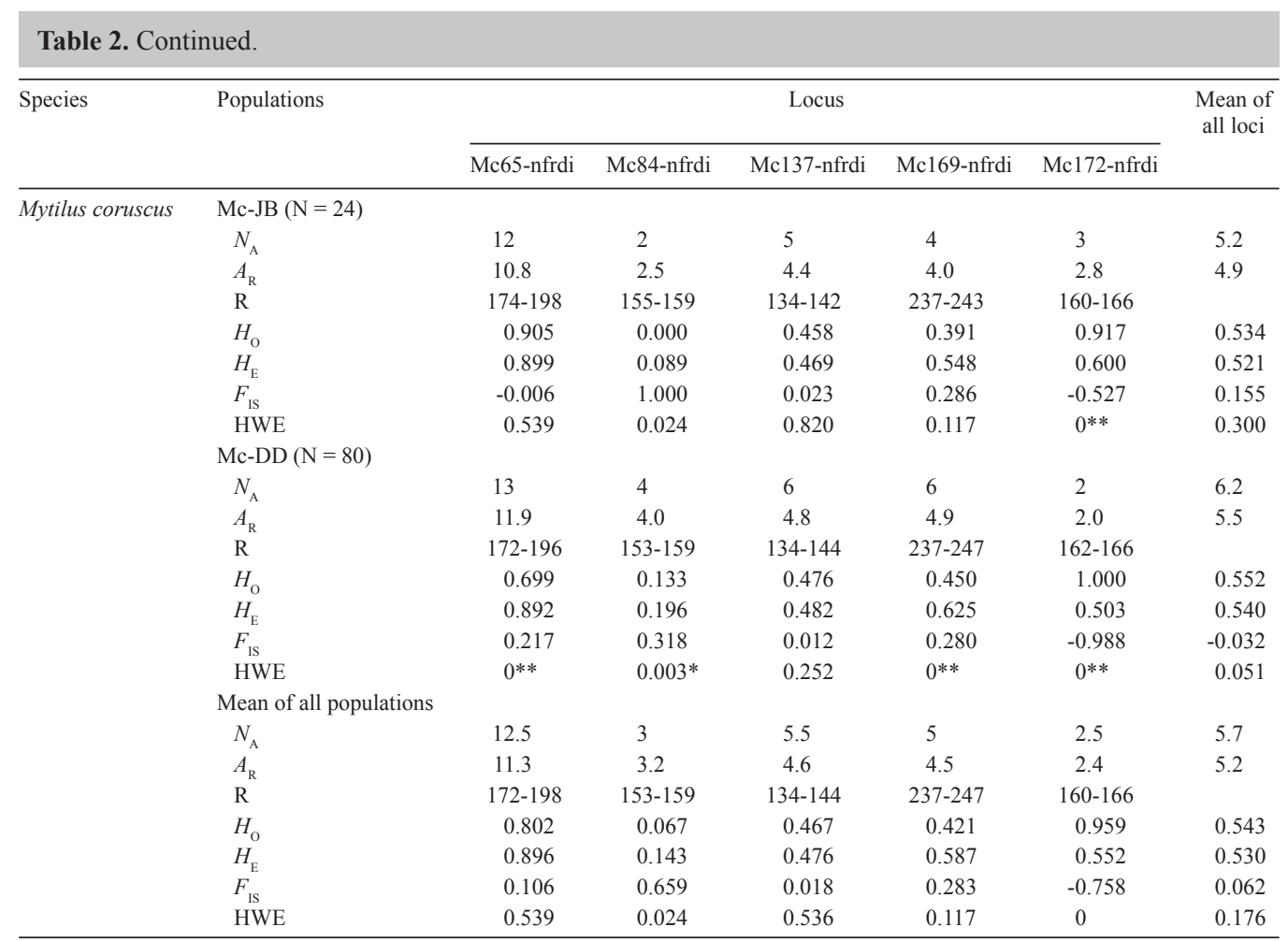

$\mathrm{N}=$ number of samples; $N_{\mathrm{A}}=$ number of alleles per locus; $A_{\mathrm{R}}=$ allelic richness; $\mathrm{R}=$ allelic size range; $H_{\mathrm{E}}=$ expected heterozygosity; $H_{\mathrm{O}}=$ observed heterozygosity. $\mathrm{HWE}=$ probability of significant deviation from Hardy-Weinberg equilibrium $(* \mathrm{P}<0.005, * * \mathrm{P}<0.001$, Bonferroni-corrected value). All genetic characterization indices are given for each population and locus.

\section{Genetic relationships among populations}

Table 3 lists the matrices of pairwise multilocus $F_{\mathrm{ST}}$ (below diagonal) and genetic distance (upper diagonal) estimates. The pairwise $F_{\mathrm{ST}}$ values showed significant genetic differences among the $6 \mathrm{M}$. galloprovincialis populations. The $\mathrm{Mg}-\mathrm{KS}$ population was significantly different from the Mg-JD, Mg-JMJ, and Mg-TA populations. Both the Mg-YD and Mg-YS populations, which were not significantly different from the Mg-KS population, were significantly different from the Mg-JD, Mg-JMJ, and Mg-TA populations, and were significantly different from each other $(\mathrm{P}<0.05)$. Both of the $M$. coruscus populations (Mc-JB and Mc-DD) were significantly different from all $6 \mathrm{M}$. galloprovincialis populations, and were significantly different from each other $(\mathrm{P}<0.05)$. The genetic distances among the $6 \mathrm{M}$. galloprovincialis populations ranged from 0.0224 to 0.1463 (average = 0.0789), while the genetic distance between the 2 M. coruscus populations was 0.0488 . An UPGMA dendrogram derived from the population analysis using the 5 MS markers revealed clear separation of $M$. coruscus and $M$. galloprovincialis. In addition, the $6 M$. galloprovincialis populations were clearly separated into 2 clusters, each with two subclusters (Figure 2). 
Table 3. Multi-locus estimates of genetic distance (upper) and $F_{\mathrm{ST}}$ (lower) among all populations of Mytilus spp after Bonferroni's correction $(\mathrm{P}<0.05)^{*}$.

\begin{tabular}{lllllllll}
\hline & \multicolumn{5}{c}{ Mytilus galloprovincialis } & & \multicolumn{2}{c}{ Mytilus coruscus } \\
\cline { 2 - 6 } \cline { 5 - 7 } & Mg-KS & Mg-JD & Mg-JMJ & Mg-TA & Mg-YD & Mg-YS & Mc-DD & Mc-JB \\
\hline Mg-KS & 0 & 0.1282 & 0.1098 & 0.0664 & 0.0224 & 0.0235 & 2.9908 \\
Mg-JD & $0.0967^{*}$ & 0 & 0.0708 & 0.0393 & 0.1337 & 0.1345 & 2.8748 & 2.0015 \\
Mg-JMJ & $0.0925^{*}$ & -0.0025 & 0 & 0.0347 & 0.0909 & 0.1463 & 3.2424 & 3.2585 \\
Mg-TA & $0.0644^{*}$ & 0.007 & 0.014 & 0 & 0.0465 & 0.0903 & 3.0119 & 3.0821 \\
Mg-YD & $0.0136^{*}$ & $0.0846^{*}$ & $0.0929^{*}$ & $0.0435^{*}$ & 0 & 0.0465 & 3.3350 & 3.3948 \\
Mg-YS & 0.0031 & $0.0865^{*}$ & $0.0777^{*}$ & $0.062^{*}$ & $0.0241^{*}$ & 0 & 2.8906 & 2.9437 \\
Mc-DD & $0.4268^{*}$ & $0.3996^{*}$ & $0.3995^{*}$ & $0.4258^{*}$ & $0.4491^{*}$ & $0.4004^{*}$ & 0 & 0.0488 \\
Mc-JB & $0.4398^{*}$ & $0.4027^{*}$ & $0.4022^{*}$ & $0.4444^{*}$ & $0.4699^{*}$ & $0.4083^{*}$ & $0.029 *$ & 0 \\
\hline
\end{tabular}

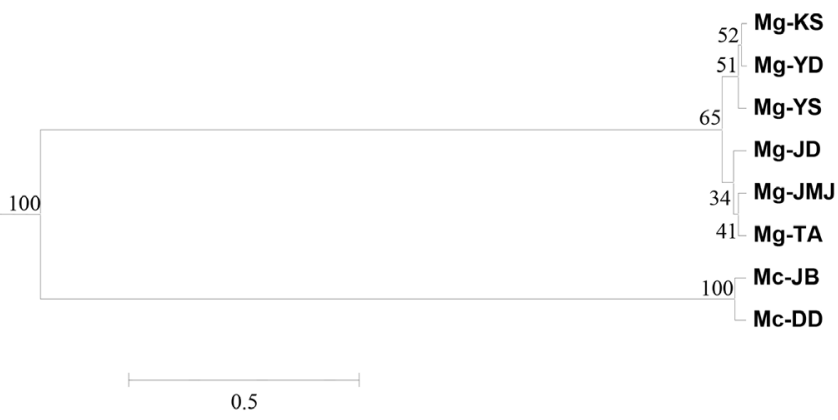

Figure 2. UPGMA tree based on matrices of pairwise Nei's genetic distances of eight microsatellite loci.

\section{Principal coordinate analysis}

Principal coordinate analysis produced a result similar to that of the cluster analysis (Figure 3). The two closely related $M$. coruscus populations were well separated from the $M$. galloprovincialis populations. The $\mathrm{Mg}-\mathrm{TA}, \mathrm{Mg}-\mathrm{JD}$, and $\mathrm{Mg}-\mathrm{JMJ}$ populations of $M$. galloprovincialis that originated from the western, southern, and eastern coasts of the Korean Peninsula formed 1 group (upper right quadrant). The $\mathrm{Mg}-\mathrm{YD}, \mathrm{Mg}-\mathrm{KS}$, and $\mathrm{Mg}$-YS populations, which also originated from 3 different coasts of the Korean Peninsula, formed the other group (lower right quadrant).

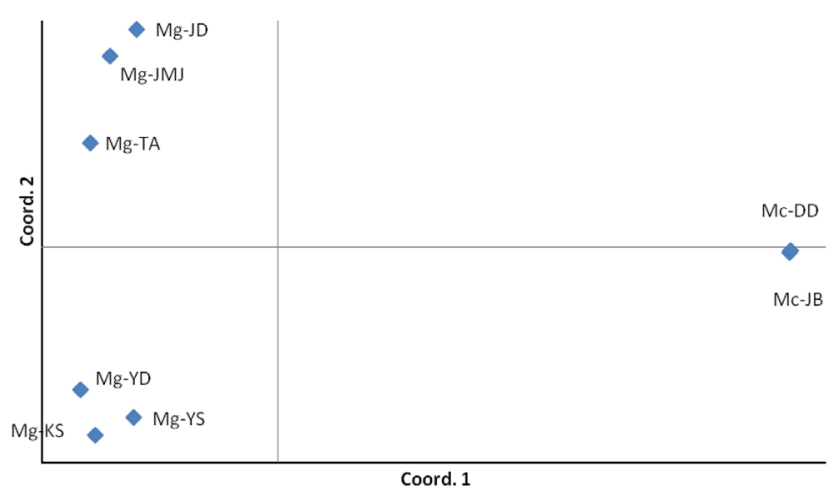

Figure 3. Principal coordinate analysis based on Nei and Li distances using five microsatellite markers from eight populations. 


\section{DISCUSSION}

The Mediterranean blue mussel, $M$. galloprovincialis, is now a major mussel species inhabiting the coastal regions of the Korean Peninsula, although the exact time and route of introduction remains uncertain. As a strong competitor, M. galloprovincialis has caused a significant reduction in the population size of the endemic Korean mussel, M. coruscus, in these coastal regions. Although M. galloprovincialis is cultured as an aquatic species, M. coruscus is preferred by gastronomists because of its large size and high-quality meat (Je et al., 1990). Current research focusing on the species restoration of $M$. coruscus requires information about the population structure and genetic diversity of this species.

A benefit of using MS markers in combination with the NGS technique is that MS markers developed for a particular species may be applied to closely related species (Barbará et al., 2007). The 5 MS markers developed for $M$. coruscus proved to be useful in the population analysis of both M. coruscus and M. galloprovincialis in the present study. The 2 species are differentiated by the shape and color of their shells (Je et al., 1990). Two populations of M. coruscus and 6 populations of $M$. galloprovincialis were first identified based on their shell characteristics, with visual identification being confirmed using partial sequence analysis of the COI gene.

Significant deviations from HWE because of excessive homozygosity were observed in most populations at 3 loci (Mc65-nfrdi, Mc84-nfrdi, and Mc172-nfrdi). Deviations from HWE have been previously reported in MS marker analyses of $M$. coruscus (Xu et al., 2010), M. galloprovincia (Diz and Presa, 2008), and other mollusk species (Hedgecock et al., 2004; Li et al., 2006; Panova et al., 2008). These deviations might arise because of one or a combination of factors, such as the substructure of samples caused by the pooling of samples from several different sites, inbreeding, or the presence of null alleles (Zouros and Foltz, 1984). The presence of null alleles is assumed to cause the heterozygote deficiency observed in several bivalve species, such as the geoduck clam, European flat oyster, and pink mucket (Launey et al., 2002; Eackles and King, 2002; Vadopalas et al., 2004). The presence of null alleles might represent a major limitation in the cross-species transfer of microsatellite markers (Barbará et al., 2007). In the present study, null alleles were identified at the same locus in both species, indicating that, in this case, the presence of null alleles might be caused by the nature of the MS locus, rather than difficulty in the cross-species transfer of MS markers.

Multi-locus $F_{\mathrm{ST}}$ estimates showed no genetic difference between the $2 \mathrm{M}$. coruscus populations collected from the east and west parts of the Korean Peninsula. M. coruscus is widely cultured throughout the coastal areas of the Bohai Sea, Yellow Sea, and East Sea in China (Xu et al., 2010), and is present in the deep sea environment (6-7 m compared to $M$. galloprovincialis living less than $3 \mathrm{~m}$ in death), where the annual water temperature is below $55^{\circ} \mathrm{C}$ (Je et al., 1990). Nevertheless, limited information is available about population genetics. To better perform resource management, population restoration, and molecular markerassisted breeding programs, further analyses of the genetic structure of M. coruscus based on samples collected from the Korean Peninsula and China are necessary.

In contrast to $M$. coruscus, significant genetic differences were observed among the $M$. galloprovincialis populations. The genetic distances among the $6 \mathrm{M}$. galloprovincialis populations ranged from 0.0224 to 0.1463 , with an average of 0.0789 . This result was further confirmed by the UPGMA dendrogram tree (Figure 2) and the principal coordinate analysis (Figure 3 ). Both of these analyses showed the separation of the 6 populations into 2 clusters containing 2 subclusters each. One interesting feature in the phylogenetic clustering was that the 2 main 
clusters contained populations from different areas of the Korean Peninsula. The first cluster contained certain populations that originated from the western (Mg-KS), eastern (Mg-YD), and southern (Mg-YS) coasts of the Korean Peninsula. In comparison, the second cluster contained different populations also from the western (Mg-TA), eastern (Mg-JMJ), and southern ( $\mathrm{Mg}$ JD) coasts. A genetic split of M. galloprovincialis populations has been documented between populations in the Atlantic Ocean and the Mediterranean Sea, with an interbasin $F_{\mathrm{ST}}$ estimate of 0.0306 (Diz and Presa, 2008). Although the relationship in the genetic separation of M. galloprovincialis in the seas around Europe and the 3 seas around the Korean Peninsula has not been elucidated, the results of this study (i.e., cluster analysis) show that more than 2 populations from different origins have been introduced to the Korean Peninsula. It is believed that M. galloprovincialis was introduced to various locations throughout the world via ship ballast water across the 20th century (Cariton and Geller, 1993). Hence, population diversification might not have been possible over the short period of time from its initial introduction to date.

Three related Mytilus species, M. edulis, M. trossulus, and M. galloprovincialis, originate from the ancestral M. trossulus (Vermeij, 1991), with hybrids of these species regularly forming (Riginos and Cunningham, 2005). Hybrids have been identified using species-specific nuclear and mitochondrial DNA PCR markers (Inoue et al., 1997; Braby and Somero, 2006; Kijewski et al., 2011). MS markers are also useful for the identification of hybrids. Among a total of 367 individuals from the 8 populations of the 2 species, no hybrids were identified when using 5 selected MS markers. One possible reason for the absence of hybrids between M. coruscus and M. galloprovincialis is the genetic distance between these 2 species. Recent evidence indicates that hybrids between $M$. galloprovincialis and M. trossulus are not reproductively viable, which might limit genetic introgression between the 2 species (Brannock et al., 2009). Another possibility for the absence of hybrids is the difference in habitat preference between M. coruscus and M. galloprovincialis. For instance, a previous study demonstrated the presence of different habitat preferences in distribution analysis of 4 species of Mytilus around the Korean Peninsula (Je et al., 1990). Within this study, the authors showed that M. coruscus is distributed in deeper and colder waters compared to M. galloprovincialis $\left(6-7 \mathrm{~m}\right.$ vs less than $3 \mathrm{~m}$ and under $15^{\circ} \mathrm{C} v s$ over $15^{\circ}-16^{\circ} \mathrm{C}$, respectively), which preferentially inhabits intertidal areas characterized by warmer temperatures and low salinity (Lockwood and Somero, 2011). Further information about the genetic structure of $M$. coruscus populations distributed around the Korean Peninsula and genetic introgression between M. coruscus and M. galloprovincialis, along with other Mytilus species, is necessary to develop rational future management and restoration programs, in addition to optimizing the selective breeding of economically and ecologically important mussel species.

\section{ACKNOWLEDGMENTS}

Research supported by grants from the National Fisheries Research and Development Institute (NFRDI) in Korea.

\section{REFERENCES}

Abdelkrim J, Robertson B, Stanton JA and Gemmell N (2009). Fast, cost-effective development of species-specific microsatellite markers by genomic sequencing. Biotechniques 46: 185-192.

Barbará T, Palma-Silva C, Paggi GM, Bered F, et al. (2007). Cross-species transfer of nuclear microsatellite markers: potential and limitations. Mol. Ecol. 16: 3759-3767. 
Brannock P, Wethey D and Hilbish T (2009). Extensive hybridization with minimal introgression in Mytilus galloprovincialis and M. trossulus in Hokkaido, Japan. Mar. Ecol. Prog. Ser. 383: 161-171.

Braby CE and Somero GN (2006). Ecological gradients and relative abundance of native (Mytilus trossulus) and invasive (Mytilus galloprovincialis) blue mussels in the California hybrid zone. Mar. Biol. 148: 1249-1262.

Cariton JT and Geller JB (1993). Ecological roulette: the global transport of nonindigenous marine organisms. Science 261: 78-82.

Diz AP and Presa P (2008). Regional patterns of microsatellite variation in Mytilus galloprovincialis from the Iberian Peninsula. Mar. Biol. 154: 277-286.

Eackles MS and King TL (2002). Isolation and characterization of microsatellite loci in Lampsilis abrupta (Bivalvia: Unionidae) and cross-species amplification within the genus. Mol. Ecol. Notes 2: 559-562.

Folmer O, Black M, Hoeh W, Lutz R, et al. (1994). DNA primers for amplification of mitochondrial cytochrome c oxidase subunit I from diverse metazoan invertebrates. Mol. Mar. Biol. Biotechnol. 3: 294-299.

Greenley AP, Muguia-Vega A, Saenz-Arroyo A and Micheli F (2012). New tetranucleotide microsatellite loci in pink abalone (Haliotis corrugata) isolated via 454 pyrosequencing. Conserv. Genet. Resour. 4: 265-268.

Griffiths CL, Hockey PAR, Van Erkom Schurink C and Roux PJL (1992). Marine invasive aliens on South African shores: implications for community structure and trophic functioning. S. Afr. J. Mar. Sci. 12: 713-722.

Guichoux E, Lagache L, Wagner S, Chaumeil P, et al. (2011). Current trends in microsatellite genotyping. Mol. Ecol. Resour. 11: 591-611.

Hamilton MB, Pincus EL, Di FA and Fleischer RC (1999). Universal linker and ligation procedures for construction of genomic DNA libraries enriched for microsatellites. Biotechniques 27: 500-507.

Hedgecock DLG, Hubert S, Bucklin K and Ribes V (2004). Widespread null alleles and poor cross-species amplification of microsatellite DNA loci cloned from the Pacific oyster, Crassostrea gigas. J. Shellfish Res. 23: 379-385.

Hilbish TJ, Mullinax A, Dolven SI, Meyer A, et al. (2000). Origin of the antitropical distribution pattern in marine mussels (Mytilus spp.): routes and timing of transequatorial migration. Mar. Biol. 136: 69-77.

Hockey PAR and Van Erkom Schurink C (1992). The invasive biology of the mussel Mytilus galloprovincialis on the southern African coast. Trans. R. Soc. S. Afr. 48: 123-139.

Inoue K, Odo S, Noda T, Nakao S, et al. (1997). A possible hybrid zone in the Mytilus edulis complex in Japan revealed by PCR markers. Mar. Biol. 128: 91-95.

Jarne P and Lagoda PJL (1996). Microsatellites, from molecules to populations and back. Trends Ecol. Evol. 11: 424-429.

Je JG, Zhang CI and Lee SH (1990). Characteristics of shell morphology and distribution of 3 species beolong to Genus Mytilus (Mytildae: Bivalvia) in Korea. Korean J. Malacol. 6: 22-32.

Kang JH, Park JY and Jo HS (2012). Rapid development of microsatellite markers with 454 pyrosequencing in a vulnerable fish, the mottled skate, Raja pulchra. Int. J. Mol. Sci. 13: 7199-7211.

Kijewski T, Śmietanka B, Zbawicka M, Gosling E, et al. (2011). Distribution of Mytilus taxa in European coastal areas as inferred from molecular markers. J. Sea Res. 65: 224-234.

Launey S, Ledu C, Boudry P, Bonhomme F, et al. (2002). Geographic structure in the European flat oyster (Ostrea edulis L.) as revealed by microsatellite polymorphism. J. Hered. 93: 331-351.

Legendre P, Borcard D, Blanchet G and Dray S (2009). PCNM: PCNM Spatial Eigenfunction and Principal Coordinate Analyses. R package version 1.10/r75. Available at [http://R-forge.R-project.org/projects/sedar/]. Accessed January 5, 2010.

Li Q, Yu H and Yu RH (2006). Genetic variability assessed by microsatellites in cultured populations of the Pacific oyster (Crassostrea gigas) in China. Aquaculture 259: 95-102.

Lockwood BL and Somero GN (2011). Invasive and native blue mussels (genus Mytilus) on the California coast: The role of physiology in a biological invasion. J. Exp. Mar. Biol. Ecol. 400: 167-174.

MIFAFF (2003). Ministry for Food, Agriculture, Forestry and Fisheries of Korea. Fisheries Information Service, Annual Statistics of Fisheries Production. Available at [http://www.fips.go.kr]. Accessed January 8, 2013.

Panova M, Mäkinen T, Fokin M, André C, et al. (2008). Microsatellite cross species amplification in the genus Littorina and detection of null alleles in Littorina saxatilis. J. Mollus. Stud. 74: 111-117.

Presa P, Pérez M and Angel PD (2002). Polymorphic microsatellite markers for blue mussels (Mytilus spp.). Conser. Gene. 3: 441-443.

Rawson PD, Agrawal V and Hilbish TJ (1999). Hybridization between the blue mussels Mytilus galloprovincialis and M. trossulus along the Pacific coast of North America: evidence for limited introgression. Mar. Biol. 134: 201-211.

Riginos C and Cunningham CW (2005). Local adaptation and species segregation in two mussel (Mytilus edulis x Mytilus trossulus) hybrid zones. Mol. Ecol. 14: 381-400.

Saarinen EV and Austin JD (2010). When technology meets conservation: increased microsatellite marker production using 454 genome sequencing on the endangered Okaloosa Darter (Etheostoma okaloosae). J. Hered. 101: 784-788. 
Sanjuan A, Carlos Z and Gonzalo A (1997). Genetic differentiong in Mytilus galloprovincialis Lmk. throughout the world. Ophelia 47: 13-31.

Santana Q, Coetzee M, Steenkamp E, Mlonyeni O, et al. (2009). Microsatellite discovery by deep sequencing of enriched genomic libraries. Biotechniques 46: 217-223.

Steffani CN, George M and Branch GM (2005). Mechanisms and consequences of competition between an alien mussel, Mytilus galloprovincialis, and an indigenous limpet, Scutellastra argenvillei. J. Exp. Mar. Biol. Ecol. 317: 127-142.

Suchanek TH, Geller JB, Kreiser BR and Mitton JB (1997). Zoogeographic distributions of the sibling species Mytilus galloprovincialis and M. trossulus (Bivalvia: Mytilidae) and their hybrids in the North Pacific. Biol. Bull. 193: 187-194.

Vadopalas B, Leclair LL and Bentzen P (2004). Microsatellite and allozyme analyses reveal few genetic differences among spatially distinct aggregations of geoduck clam (Panopea abrupta, Conrad 1849). J. Shellfish Res. 23: 693-706.

Vermeij G (1991). Anatomy of an invasion: the trans-Arctic interchange. Paleobiology 17: 281-307.

Wang J, Yu X, Zhao K, Zhang Y, et al. (2012). Microsatellite Development for an endangered bream Megalobrama pellegrini (Teleostei, Cyprinidae) using 454 sequencing. Int. J. Mol. Sci. 13: 3009-3021.

Wonham MJ (2004). Mini-review: distribution of the Mediterranean mussel Mytilus galloprovincialis (Bivalvia: Mytilidae) and hybrids in the Northeast Pacific. J. Shellfish Res. 23: 535-543.

Xu TJ, Sun YN, Yuan YT, Liao Z, et al. (2010). Isolation and characterization of polymorphic microsatellite loci in the hard-shelled mussel, Mytilus coruscus (Mytilidae). Genet. Mol. Res. 9: 1388-1391.

Zalapa JE, Cuevas H, Zhu H, Steffan S, et al. (2012). Using next-generation sequencing approaches to isolate simple sequence repeat (SSR) loci in the plant sciences. Am. J. Bot. 99: 193-208.

Zane L, Bargelloni L and Patarnello T (2002). Strategies for microsatellite isolation: a review. Mol. Ecol. 11: 1-16.

Zouros E and Foltz DW (1984). Possible explanations of heterozygote deficiency in bivalve mollusks. Malacologia 25: 583-591. 